\title{
Adoptive transfer of tumor specific T cells from allogeneic donors is feasible, effective and safe alternative to autologous $\mathrm{T}$ cell based tumor immunotherapy
}

\author{
Eliza P. Kwiatkowska-Borowczyk',2, Anna Kozłowska', Klaudia Maruszak³, Luiza Kańczuga- \\ $-K_{0} a^{3}$, Mariusz Koda ${ }^{3}$, Monika Dajnowiec ${ }^{4}$, Andrzej Mackiewicz'1, ${ }^{1}$, Dariusz W. Kowalczyk ${ }^{4,5}$ \\ ${ }^{1}$ Department of Cancer Immunology, Poznan University of Medical Sciences, Poland \\ ${ }^{2}$ Diagnostic and Immunology Department, Greater Poland Cancer Centre, Poznan, Poland \\ ${ }^{3}$ Department of Pathology, MSW Hospital, Olsztyn, Poland \\ ${ }^{4}$ Department of Pathophysiology, Faculty of Medicine, University of Warmia and Mazury in Olsztyn, Poland
}

\begin{abstract}
Donor lymphocyte infusion is used to increase the graft versus tumor (GVT) effect after allogeneic hematopoietic cell transplant. The limited spectrum of activity and high risk of graft versus host disease (GVHD) remain major limitations of this approach. The finding of new cell populations for adoptive immunotherapy, with the ability to separate GVT from GVHD, would be useful. In the present manuscript, we tested in mouse model the use of allogeneic MHC partially matched effector cells for adoptive T cell immunotherapy of cancer. We sought to maximize graft-versus-tumor effect while minimizing GVHD using tumor-specific allogeneic effector $T$ cells rather than open-repertoire T cells. A F1 hybrid (Balb/c x C57BL/6) -MethA-EGFP-bearing mice received a preparative regimen of nonmyeloablating cyclophosphamide lymphodepletion followed by adoptive transfer of bulk Balb/c derived allogeneic $T$ cells specific for the MethA-EGFP tumor cells. Adoptively transferred allogeneic tumorspecific $T$ lymphocytes prevented tumor formation without graft versus host disease - like symptoms. We found that the risk of GVHD was low even with high number of transferred tumor-specific T cells. These data indicate that the use of tumor-specific allogeneic $T$ cells is feasible, effective and safe alternative to autologous $T$ cell based tumor immunotherapy.
\end{abstract}

Key words: adoptive cell transfer, tumor immunotherapy, cancer, GVHD, allogeneic T cells, murine model.

\section{Introduction}

Allogeneic bone marrow or stem cell transplantation can be considered the most successful method of adoptive immunotherapy of malignances. Its success appears to be related in part to the graft-versus-tumor (GVT) potential of the donor graft. Donor T-cells may recognize leukemic specific or recipient specific alloantigens and eliminate residual malignant cells (graft versus leukemia). This T-cell reaction can be harnessed in some cases to treat patients who relapse after allogeneic stem cell transplantation with the use of donor leukocyte infusions (DLIs). Unfortunately, the effects of GVT have clear disease specificity. Despite its therapeutic potential in hematologic malignancies most solid tumors have proven to be resistant to this therapy [1-8]. Thus, GVT induction in solid tumors require a better understanding of the important target antigens and effector cells, as well as the development of methods that enhance GVT reactivity without excessive GVHD.

A factor that might be important in GVT is donor $\mathrm{T}$ cell tumor specificity. In DLI vast majority of T cells do not have any specific tumor reactivity, have unknown 
antigen specificity and possess an intrinsic danger of GVHD induction. The absence of defined antigen specificity of such $T$ cells makes them difficult to reproducibly create a therapeutic window between GVT and GVHD. In contrary to DLI tumor infiltrating lymphocytes (TIL) may contain T cells with antitumor activity. Indeed, adoptive cell transfer (ACT) of TIL amplified in vitro, in association with lymphodepleting chemotherapy and IL-2, has been shown to mediate regression of large established tumors [1-2]. Despite its clinical efficacy this approach is still experimental treatment for patients with metastatic melanoma. Its wide use is limited by the fact that cells must be obtained through a surgical procedure, followed by the process of ex vivo expansion, which is difficult, labor intensive and it is not always feasible to yield $T$ cells in amount sufficient for clinical purposes [3]. Allogeneic donor tumor-specific T-cells partially matched for recipient MHC antigens could provide an alternative to autologous TIL therapy.

The use of allogeneic antigen specific T cell therapy has been already reported. It was shown that allogeneic TILs sharing an MHC restriction element for a common tumor antigen can be used to successfully treat established metastases in the nonallosensitized host [7]. Additional preclinical results used an experimental model of melanoma treated with transgenic antigen specific allogeneic major histocompatibility complex (MHC)-mismatched T-cell. These adoptively transferred allogeneic tumor-specific T lymphocytes persisted at detectable levels for several weeks and mediated significant regression of large, vascularized tumors [9]. Together, these results encourage the implementation of further studies assessing the safety and clinical efficacy of tumor specific $T$ cells administered to cancer patients bearing antigen-expressing tumors. The use of this strategy raises two major concerns: the survival of the effectors and the risk of development of lethal graft versus host disease. Whereas the persistence of transferred cells might be crucial for a favorable clinical outcome [10-12], the use of allogeneic T cells in immunocompromised host have a high risk of deleterious graft versus host disease which is a major, potentially life threatening complication. The most important factor predicting the risk of GVHD is MHC disparity between the donor and recipient. Therefore in cases with only partial MHC matching the probability of GVHD after ACT might be potentially very high. Although it was found that the risk of GVHD was low when allogeneic tumor-specific T cells were transferred however this study was based on transgenic antigen specific T cells where the majority of transferred cells had well defined antigen specificity. In clinical situation allogeneic tumor reactive $T$ cells may have unknown specificity and possess a potential danger of inducing lethal GVHD. In the present paper, we sought to explore the feasibility of using tumor-specific allogeneic T cells in the treatment of the experimental mouse sarcoma MethA, after a preparative lymphodepletion regimen with cyclophosphamide (CPA). We tried to simulate clinical condition with in vivo antigen $\mathrm{T}$ cell priming followed by in vitro expansion and semiallogeneic adoptive transfer. We studied the ability of allogeneic cells to reject tumor cells and explored the risk of inducing GVHDlike reactions when tumor primed allogeneic $T$ cells are used as a cell source.

\section{Material and methods}

Mice and tumor lines

All mice used in these experiments were housed at the Animal Facility of University of Medical Sciences, Poznan. Female Balb/c $\left(\mathrm{H}-2^{\mathrm{d} / \mathrm{d}}\right)$ and $\mathrm{F} 1$ hybrid Balb/c $x$ C57BL/6 $\left(\mathrm{H}-2^{\mathrm{b} / \mathrm{d}}\right)$ mice were used. Female F1 hybrid $\mathrm{Balb} / \mathrm{c} \times \mathrm{C} 57 \mathrm{BL} / 6$ and Balb/c wild-type were used as recipients in $A C T$ experiments. Balb/c mice $\left(H-2^{d / d}\right)$ were used as a source of donor cells. All mice were purchased Mossakowski Medical Research Centre Polish Academy of Sciences, Warsaw, Poland.

The MethA-EGFP tumor cell line is derived from a chemically induced sarcoma in Balb/c mouse $\left(\mathrm{H}-2^{\mathrm{d}}\right)$ and expresses the EGFP antigen [16, 17] MethA-EGFP cells were maintained in culture at $37^{\circ} \mathrm{C}$ in $5 \% \mathrm{CO}_{2}$ in CMM. Experiments were conducted with the approval of the University of Medical Science Animal Use and Care Committee according to national regulations.

In vitro expansion of anti-MethA-EGFP specific T cells Anti-MethA-EGFP T cells were isolated from spleens of Balb/c donor mice immunized twice with $10^{6}$ irradiated (10Gy) MethA-EGFP cells in weekly intervals. After 8-10 days splenocytes were isolated and cultured in the presence of briostatin $(5 \mathrm{nM})$, ionomycin $(1 \mu \mathrm{M})$ and IL-2 $(80 \mathrm{U} / \mathrm{ml})$ in X-Vivo 10 medium for 16 hours. Then, bulk T cell cultures were plated at $10^{6}$ cells $/ \mathrm{mL}$ in X-Vivo 10 medium with IL-7 $(20 \mathrm{ng} / \mathrm{ml})$ and IL-15 (20 ng/ml). After next 24 hours the medium was supplemented with IL-2 $(20 \mathrm{U} / \mathrm{ml})$. The cells were split 1:1 when they reach $3 \times 10^{6}$ cells $/ \mathrm{ml}$ density. After $4-6$ days the cells were further stimulated with anti-CD3 and anti-CD28 antibodies (Dynabeads Mouse CD3/CD28 T-cell Expander, Invitrogen) and used for adoptive transfer 10-18 days after the start of the culture. 
MethA-EGFP tumor challenge

and adoptive cell transfer

$\mathrm{F} 1 \mathrm{Balb} / \mathrm{c} \times \mathrm{C} 57 \mathrm{Bl} / 6$ mice 6 to 12 weeks of age ( $\mathrm{n}=$ 5-6 for all groups) were injected subcutaneously with $5 \times 10^{5}$ MethA-EGFP sarcoma cells and treated with intravenous adoptive transfer of in vitro-activated MethA-EGFP specific $T$ cells derived from parental Balb/c donors as indicated. Lymphopenia was induced by nonmyeloablative cyclophosphamide (CPA) administration $(100 \mathrm{mg} / \mathrm{kg})$ one day before the cell transfer. Tumor growth was measured twice weekly in a blinded, randomized fashion. All experiments were performed independently at least twice, with similar results.

Characterization of in vitro expanded T-cells and cell trafficking in vivo

Cellular phenotypes were determined by flow cytometric analysis after staining with antibodies specific for CD3, CD4, CD8, CD49a, CD25, CD69, CD44, CD122, CD127 antigens (BD Pharmingen). For in vivo trafficking $T$ cells were stained in vitro with CellTrace Far Red DDAO-SE (Molecular Probes, Eugene, OR, USA) and injected intravenously to BALB/C mice. Injected mice were analyzed with IVIS Spectrum whole live-animal imaging system (Perkin Elmer Inc., Waltham, MA, USA). Mice were anesthetized with isoflurane using a vaporizer, and fluorescent image was obtained using appropriate filter set.

\section{Histology}

Livers, small intestines, and skin from killed ACT recipients were fixed in 10\% buffered neutral formalin, embedded in paraffin, sectioned at $5 \mu \mathrm{m}$, and stained with hematoxylin and eosin. Images were obtained using a Nikon Eclipse E400 microscope (Tokyo, Japan) equipped with Nuance Multispectral Imaging System VIS and related software (CRI, Woburn, MA). Original magnification was $\times 100$.

\section{Results}

To test whether allogeneic tumor-specific T cells could be effectively used to treat tumors, we created an allogeneic adoptive immunotherapy model based on the MethA-EGFP system that we previously described [17].
T cells from MethA-EGFP immune Balb/c mice recognize unidentified MethA tumor antigens as well as the $\mathrm{H}-2^{\mathrm{d}}$-restricted epitope of the EGFP antigen corresponding to amino acids 200 to 208 that is expressed in MethA-EGFP sarcoma tumor [16]. To create a source of tumor-specific allogeneic effector cells, we immunized Balb/c mice $\left(\mathrm{H}-2^{\mathrm{d}}\right)$ with syngeneic, irradiated MethA-EGFP tumor cells. To assess the ability of allogeneic effector cells to reject tumor cells in MHC-mismatched hosts, we transferred Balb/c derived and in vitro expanded anti-MethA-EGFP T cells into F1 Balb/c x C57BL/6 mice that received $100 \mathrm{mg} / \mathrm{kg}$ CPA as lymphodepleting regimen before the transfer. The administration of $100 \mathrm{mg} / \mathrm{kg}$ CPA is a well-established conditioning regimen that induces a profound but transient lymphodepletion lasting for 7 to 10 days [18, 19]. This dose has previously been shown to augment the effectiveness of adoptive cell transfer therapy in various models through several mechanisms, including the removal of immunoregulatory elements, "cytokine sinks", and activation of antigen-presenting cells [18]. Through this approach we wanted to induce a sufficient degree of immunosuppression that would enable the engraftment and in vivo expansion of allogeneic $T$ cells. Since the use of allogeneic $T$ cell has a risk of GVHD, the second objective was to study the influence of allogeneic adoptive cell transfer on GVHD development.

\section{Phenotype of expanded T-cells}

T-cell cultures consisted of cells with morphological features typical of activated $T$ cells. The presence or absence of various immune cell types was evaluated by flow cytometric analysis for markers including CD3, CD4, CD8, CD49a, CD25, CD69, CD44, CD122, CD127. As expected, CD3+ T cells were the predominant cell type with majority of cells expressing CD4 marker. CD8+ cells accounted for less than $10 \%$ of the cell population. Constantly all cells in culture showed expression of the CD44 antigen which is effectormemory T-cell cell marker. CD25 activation marker was present on $88 \%$ of CD $8+$ and $40 \%$ of CD $4+$ cells. The CD122 antigen $75-k D a$ subunit of the high-affinity interleukin-2 receptor (IL-2R) was detected on $98 \%$ of CD8+ and $80 \%$ of CD4+ cells respectively.

Table 1. Immunophenotype of T cells used for ACT

\begin{tabular}{lcccccccc}
\hline T cell marker & CD3 & CD4 & CD8 & CD25 & CD44 & CD49a & CD122 & CD127 \\
\hline$\%$ & 99 & 74 & 6,5 & $\begin{array}{l}40 \text { (CD4) } \\
88 \text { (CD8) }\end{array}$ & \multirow{2}{*}{99} & \multirow{2}{*}{50} & 80 (CD4) & 86 (CD4) \\
& & & & & & \\
\hline
\end{tabular}




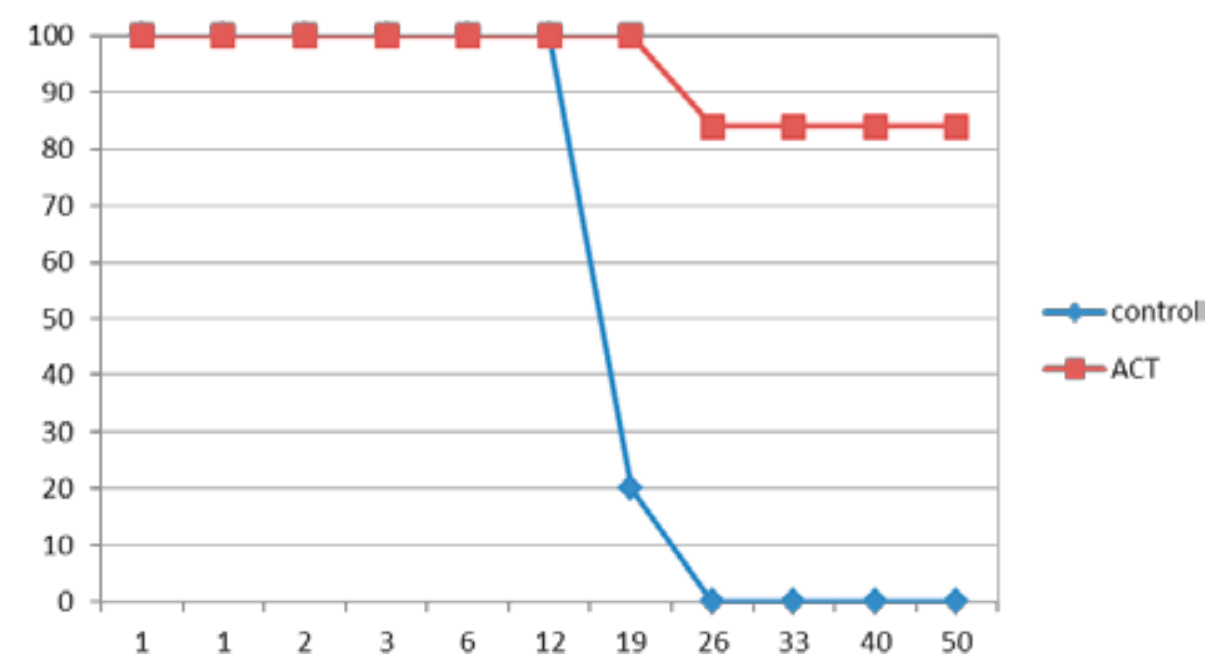

Figure 1. Allogeneic tumor-specific lymphocytes prevent tumor formation. F1 Balb/c x C57BL/6 mice were injected s.c. with MethA-EGFP tumor cells and subjected to ACT with semi-allogeneic in vitro expanded T cell effectors (as indicated). All groups received $100 \mathrm{mg} / \mathrm{kg}$ of CPA as a preconditioning the day before the transfer of the effector cells (day 1). Results of tumor formation are the observation of at least 5 mice per group. Data are representative of 3 independent experiments
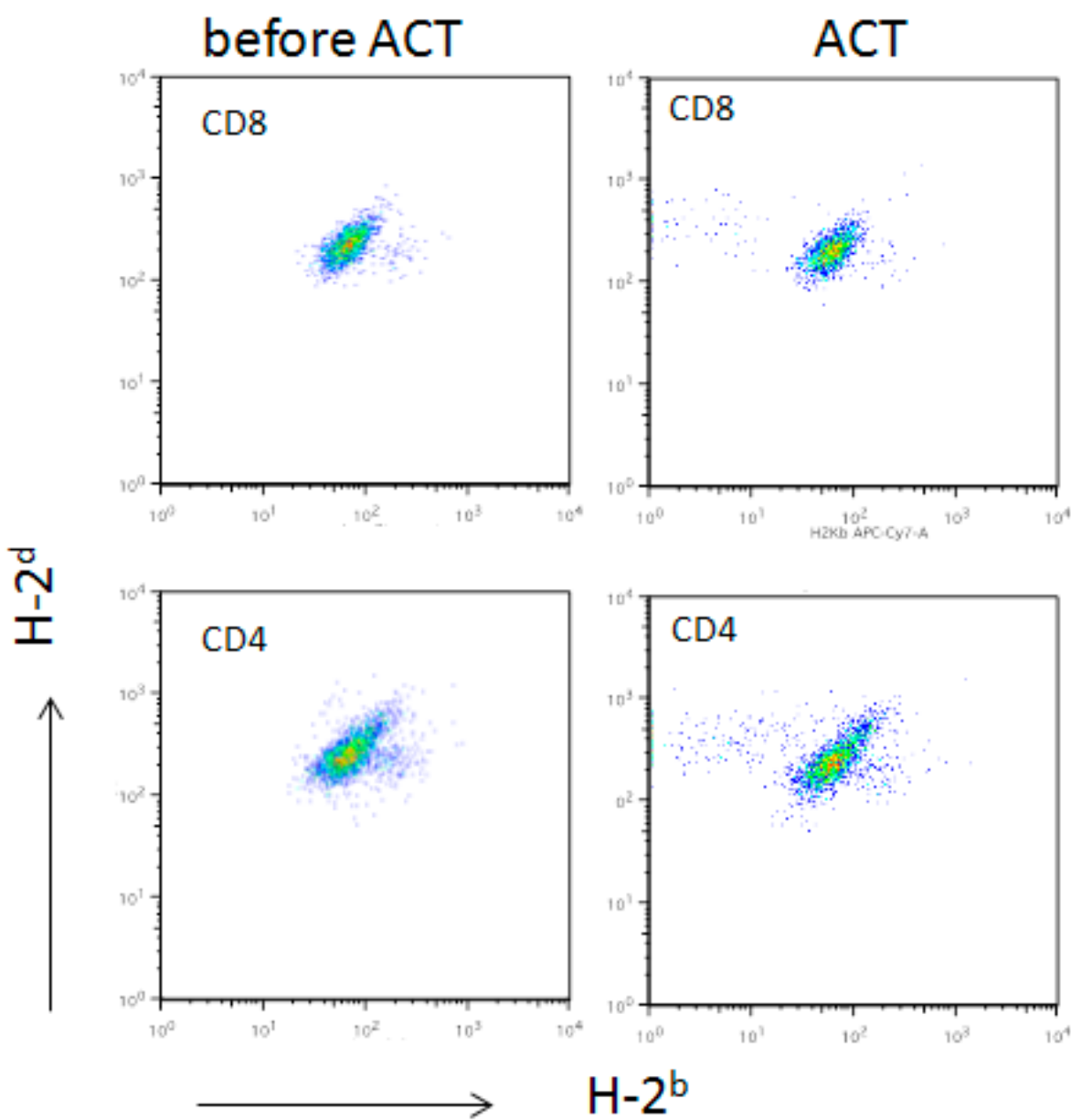

Figure 2. Allogeneic antitumor T lymphocyte persistence in vivo. F1 Balb/c x C57BL/6 mice were treated with $20 \times 10^{6}$ allogeneic anti-MethA-EGFP T cells. After 21 days, mice were killed, and the spleens were analyzed by flow cytometry for the presence of the transferred cells. The dot plots show the percentage of transferred $\mathrm{H}-2^{\mathrm{d} / \mathrm{d}} \mathrm{T}$ cells among predominant $\mathrm{H}-2^{\mathrm{b} / \mathrm{d}}$ host cells. Allogeneic cells were detectable up to day 42 after transfer. Data are representative of 3 independent experiments 
a

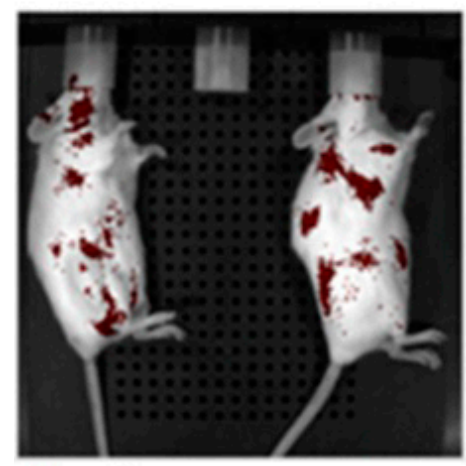

C

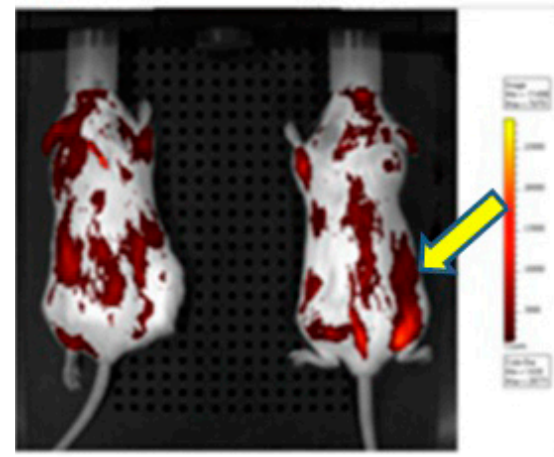

b

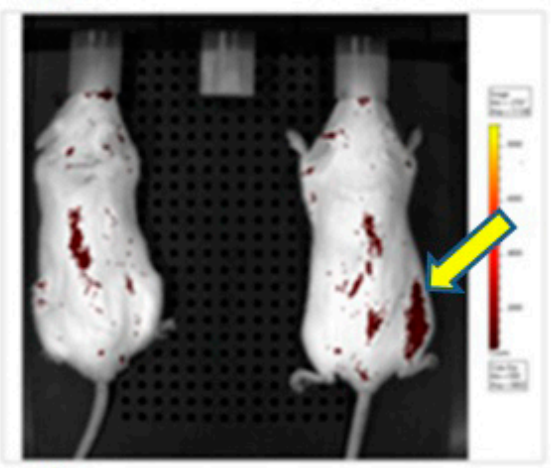

d

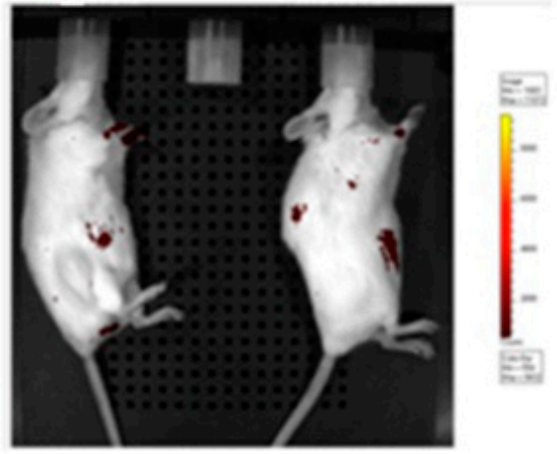

Figure 3. Engraftment, biodistribution and viability of effector cells in vivo. Anti-MethA-EGFP effector cells were expanded in vitro, labeled with CellTrace Far Red DDAO-SE and transferred into MethA-EGFP tumor bearing mice. Images were taken using IVIS-Spectrum Imaging System after 2(a), 24(b), 48(c) and 120(d) hours. Please note selective accumulation at tumor site (arrows, panel $b, c$ )

Allogeneic effector cells prevent tumor formation The aim of this study was to investigate the ability of allogeneic effector cells to reject implanted tumor cells in vivo. We used Balb/c derived $T$ cells to treat MethA-EGFP-bearing F1 Balb/c x C57BL/6 mice. The exogenous lymphocytes present in the recipient may recognize syngeneic tumor cells and allogeneic $\mathrm{MHC}$ molecules expressed by the host organs. This model eliminates the possibility of a rejection of the donor cells because F1 lymphocytes are tolerant to all antigens in the Balb/c background, however GVHD-like reaction from parental donor Balb/c cells against recipients remains efficient. Tumor cells were implanted subcutaneously and recipient mice were preconditioned with $100 \mathrm{mg} / \mathrm{kg}$ CPA one day before the transfer.

$5 \times 10^{6}$ in vitro expanded allogeneic haploidentical effector cells considerably prevented tumor formation without any evidence of GVHD-like reaction. Increasing the dose of allogeneic effector cells by 4 -fold (i.e., $2 \times 10^{7}$ cells instead of $5 \times 10^{6}$ ) led to a better tumor treatment still without any measurable toxic effect.
Allogeneic effector cells persist in vivo In next set of experiments, we analyzed the animals at different time points for the presence of allogeneic $\mathrm{T}$ cells expressing the $\mathrm{MHC}$ class I $\mathrm{H}-2^{\mathrm{d} / \mathrm{d}}$ molecule. In mice that received CPA pretreatment, allogeneic donor $T$ cells were clearly detectable up to 42 days after transfer. Transferred lymphocytes were also present at the tumor site, indicating that they not only persisted but were capable of trafficking to peripheral sites. These data indicated that allogeneic effector cells can engraft for relatively long periods after a conditioning regimen and preserved the ability to infiltrate tumor tissue.

The risk of inducing a GVHD-like reaction is minimal when the T cell specificity is confined Alloantigen reactive $T$ cells can lead to severe, lifethreating GVHD. Host immune suppression by a lymphodepleting regimen before cell transfer makes this conditions even more plausible $[1,18]$. As such, adoptive cell transfer with allogeneic antitumor $\mathrm{T}$ cells possess a potential danger for inducing a GVHD-like reaction. Theoretically, because the anti-MethA-EGFP TCRs 

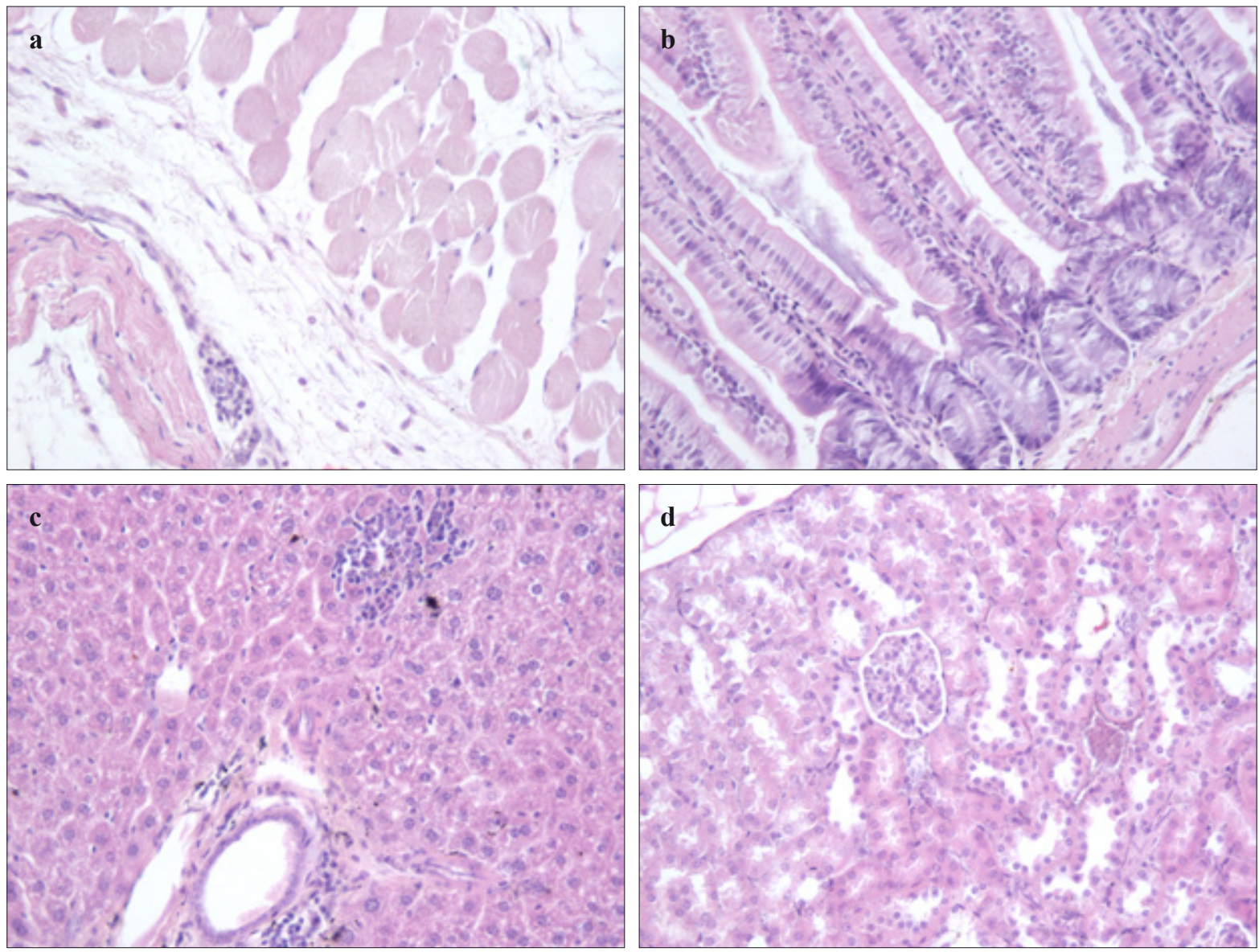

Figure 4. Lack of GVHD-like reactions after parental Balb/c to F1 Balb/c x C57BL/6 tumor specific T cell transfer. In all experiments, in vitro expanded tumor specific $T$ cells were given to cyclophosphamide treated $F 1$ recipients. Skin $-A$, intestine $-B$, liver $-C$, and kidney $-D$ tissue samples were analyzed by histopathology for manifestation of GVHD

are selected on the $\mathrm{H}-2^{\mathrm{d}} \mathrm{MHC}$ class I molecule, they could cross-react with self-antigens expressed on a different haplotype or even to react with a different MHC class I antigens in a peptide-independent manner [20]. The ability of anti-MethA-EGFP cells to react against recipient cells expressing $\mathrm{H}-2^{\mathrm{b}} \mathrm{MHC}$ antigens could be tested in vitro with Balb/c cells co-cultured with irradiated splenocytes derived from C57BL/6 or $\mathrm{F} 1 \mathrm{Balb} / \mathrm{c}$ $x$ C57BL/ 6 mice in the presence or the absence of the relevant EGFP peptide. Activation induced CD 49b and/ or IFN-g expression could be observed only in the presence of the relevant peptide and the proper restriction element $\left(\mathrm{H}-2^{\mathrm{d}}\right)$, suggesting that the anti-MethA-EGFP TCR cross-reactivity with allogeneic antigens is minimal. However, many more self-antigens are presented in vivo; thus, this kind of in vitro mixed leukocyte reaction might not be an accurate predictor of what would happen after transfer in a living host. A small number of non-tumor-specific $T$ cells might contaminate cell cultures, even after several rounds of in vitro expansions and selection. To address this point, we transferred anti-MethA-EGFP cells into CPA treated semi-allogeneic $\mathrm{F} 1 \mathrm{Balb} / \mathrm{C} \times \mathrm{B} 6\left(\mathrm{H}-2^{\mathrm{b} / d}\right)$ or CPA treated syngeneic Balb/c $\left(H-2^{d / d}\right)$ mice as a control. Transfer of in vitro expanded anti-MethA-EGFP T cells in doses between $5 \times 10^{6}$ up to $20 \times 10^{\wedge} 6$ did not result in any measurable toxicity as measured by weight loss, general behavior, survival and histopathology examination. These experiments show that the risk of GVHD is small when allogeneic effector $T$ cells with defined antigen specificity are used.

\section{Discussion}

Antitumor $\mathrm{T}$ cells has the clinical potential to treat malignancy, both in the setting of autologous TIL for solid tumors and with the use of DLI in hematologic malignancies. Whereas allogeneic adoptive immunotherapy can be quite powerful, many issues remain to be determined for optimization of GVT activity. It is not known whether the GVT reaction is a generalized allogeneic effect or has disease-specific targets, and it 
has not yet been possible to consistently separate GVT from GVHD.

In the present study, we tested in animal model the potential use of allogeneic MHC partially matched effector T cells for adoptive tumor immunotherapy. Our results indicate that tumor reactive allogeneic $T$ cells can be obtained and expanded in a relatively easy way, they exhibit antitumor activity in vivo and do not induce severe GVHD. Therefore, this approach seems to be feasible, effective and safe and might bridge allogeneic DLI with autologous TIL therapy.

In our model majority of in vitro expanded allogeneic T cells express CD4+ phenotype, which persists in vivo and mediate antitumor effect despite the absence of MHC class II antigens on tumor cells. Although definitive conclusions are not easy to draw with the currently available data, these findings might be explained by the ability of $T$ helper cells to recruit and activate endogenous effector cells from both the innate and adaptive branch of the immune system to the tumor site [23-25]. In addition, CD4+ T cells through activation of dendritic cells facilitate the priming of specific antitumor CD8+ $T$ cells in the tumor-draining lymph nodes [26-28]. Thus, the requirement for direct tumor recognition might be of lesser importance for antitumor CD4+ T cell-based therapies, making allogeneic T helper cells a particularly viable approach deserving a more detailed investigation.

In our experiments we did not detect any signs of GVHD. Our data indicate that the risk of adverse reaction because of "off target" recognition may be low if antigen specific $T$ cells are used. The risk of severe life threating GVHD increases with the number of $T$ cells infused. Patients treated with high-dose donor lymphocyte infusion developed severe adverse reactions and died of GVHD and bone marrow failure [36]. Thus, it might be useful either to screen allogeneic T-cell effectors and remove those cells that are alloreactive or alternatively expand tumor specific T cells [36-38]. In our study antitumor $\mathrm{T}$ cells generated from immune mice had effector memory phenotype and due to define antigen specificity possess a limited TCR repertoire, therefore the risk of GVHD in this setting should be considerably lower even with high cell number. Several reports have shown that naive $T$ cells are much more efficient in initiating graft-versus-host reaction compared with memory T cells [40-43].

In conclusion: there are several reasons that make antigen specific allogeneic adoptive $T$ cell transfer appealing. Relatively easy and unsophisticated method of in vitro preparation ensures improved selection, standardization, quality and safety controls required for clinical products. For selected and common haplotypes the establishment of a bank of highly reactive tumorspecific $\mathrm{T}$ cells would allow for massive or standardized treatment. Moreover, multiple, repetitive administrations might be also possible.

Taken together, our findings show that allogeneic $\mathrm{T}$ cells might have a potential role in the cell-based immunotherapy of cancer.

Supported by NCN grant: N N401 456537.

\section{References}

1. Dudley ME, Wunderlich JR, Yang JC et al. Adoptive cell transfer therapy following non-myeloablative but lympho-depleting chemotherapy for the treatment of patients with refractory metastatic melanoma. J Clin Oncol. 2005;23:2346-2357.

2. Rosenberg SA, Restifo NP, Yang JC, Morgan RA, Dudley ME. Adoptive cell transfer: a clinical path to effective cancer immunotherapy. Nat Rev Cancer. 2008;8:299-308.

3. Dudley ME, Wunderlich JR, Shelton TE, Even J, Rosenberg SA. Generation of tumor-infiltrating lymphocyte cultures for use in adoptive transfer therapy for melanoma patients. J Immunother. 2003;26:332-342.

4. Wynn RF, Arkwright PD, Haque $T$ et al. Treatment of Epstein-Barr-virus-associated primary CNS B cell lymphoma with allogeneic T-cell immunotherapy and stem-cell transplantation. Lancet Oncol. 2005;6:344-346.

5. Haque T, Wilkie GM, Taylor C et al. Treatment of Epstein -Barr-virus-positive post-transplantation lymphoproliferative disease with partly HLA-matched allogeneic cytotoxic T cells. Lancet. 2002;360:436-442.

6. Haque T, Wilkie GM, Jones MM et al. Allogeneic cytotoxic T-cell therapy for EBV-positive posttransplantation lymphoproliferative disease: results of a phase 2 multicenter clinical trial. Blood. 2007;110:1123-1131.

7. Bartels CJ, Rosenberg SA, Yang JC. Adoptive cellular immunotherapy of cancer in mice using allogeneic T-cells. Ann Surg Oncol. 1996;3:67-73.

8. Zakrzewski JL, Suh D, Markley JC et al. Tumor immunotherapy across MHC barriers using allogeneic T-cell precursors. Nat Biotechnol. 2008;26:453-461.

9. Boni A, Muranski P, Lydie Cassard, Wrzesinski C, Paulos CM, Palmer DC, Gattinoni L, Hinrichs CS, Chan CC, Rosenberg SA, Restifo NP. Adoptive transfer of allogeneic tumor-specific $T$ cells mediates effective regression of large tumors across major histocompatibility barriers. Blood. 2008; 112: 4746-4754.

10. Gattinoni L, Powell DJ, Jr, Rosenberg SA, Restifo NP. Adoptive immunotherapy for cancer: building on success. Nat Rev Immunol. 2006;6:383-393.

11. Huang J, Khong HT, Dudley ME et al. Survival, persisten$\mathrm{ce}$, and progressive differentiation of adoptively transferred tumor-reactive $T$ cells associated with tumor regression. J Immunother. 2005;28:258-267.

12. Zhou J, Shen X, Huang J, Hodes RJ, Rosenberg SA, Robbins PF. Telomere length of transferred lymphocytes cor- 
relates with in vivo persistence and tumor regression in melanoma patients receiving cell transfer therapy. J Immunol. 2005;175:7046-7052.

13. Lee TH, Donegan E, Slichter S, Busch MP. Transient increase in circulating donor leukocytes after allogeneic transfusions in immunocompetent recipients compatible with donor cell proliferation. Blood. 1995;85:1207-1214.

14. Adams PT, Davenport RD, Reardon DA, Roth MS. Detection of circulating donor white blood cells in patients receiving multiple transfusions. Blood. 1992;80:551-555.

15. Leitman SF, Tisdale JF, Bolan CD et al. Transfusion-associated GVHD after fludarabine therapy in a patient with systemic lupus erythematosus. Transfusion. 2003;43:1667-1671.

16. Gambotto A, Dworacki G, Cicinnati V, Kenniston T, Steitz J, Tüting $T$, Robbins PD, DeLeo AB. Immunogenicity of enhanced green fluorescent protein (EGFP) in BALB/C mice: identification of an $\mathrm{H} 2-\mathrm{Kd}$-restricted CTL epitope. Gene Ther. 2000;7:2036-40.

17. Wysocki PJ, Kwiatkowska EP, Kazimierczak U, Suchorska W, Kowalczyk DW, Mackiewicz A. Captopril, an angiotensin-converting enzyme inhibitor, promotes growth of immunogenic tumors in mice. Clin Cancer Res. 2006;12:4095-102.

18. Gattinoni L, Finkelstein SE, Klebanoff CA et al. Removal of homeostatic cytokine sinks by lymphodepletion enhances the efficacy of adoptively transferred tumorspecific CD8+ T cells. J Exp Med. 2005;202:907-912.

19. Wrzesinski C, Paulos CM, Gattinoni L et al. Hematopoietic stem cells promote the expansion and function of adoptively transferred antitumor CD8 T cells. J Clin Invest. 2007;117:492-501.

20. Felix NJ, Allen PM. Specificity of T-cell alloreactivity. Nat Rev Immunol. 2007;7:942-953.

21. Gattinoni L, Klebanoff CA, Palmer DC et al. Acquisition of full effector function in vitro paradoxically impairs the in vivo antitumor efficacy of adoptively transferred CD8+ T cells. J Clin Invest. 2005;115:1616-1626.

22. Klebanoff CA, Gattinoni L, Restifo NP. CD8+ T-cell memory in tumor immunology and immunotherapy. Immunol Rev. 2006;211:214-224.

23. Wong SB, Bos R, Sherman LA. Tumor-specific CD4+ T cells render the tumor environment permissive for infiltration by low-avidity CD8+ T cells. J Immunol. 2008;180:3122-3131.

24. Ossendorp F, Mengede E, Camps M, Filius R, Melief CJ. Specific $T$ helper cell requirement for optimal induction of cytotoxic $T$ lymphocytes against major histocompatibility complex class II negative tumors. J Exp Med. 1998;187:693-702.

25. Corthay A, Skovseth DK, Lundin KU et al. Primary antitumor immune response mediated by CD4+ T cells. Immunity. 2005;22:371-383.

26. Janssen EM, Lemmens EE, Wolfe $T$, Christen $U$, von Herrath MG, Schoenberger SP. CD4+ T cells are required for secondary expansion and memory in CD8+ T lymphocytes. Nature. 2003;421:852-856.

27. Shedlock DJ, Shen H. Requirement for CD4 T cell help in generating functional CD8 $\mathrm{T}$ cell memory. Science. 2003;300:337-339.

28. Smith CM, Wilson NS, Waithman J et al. Cognate CD4(+) T cell licensing of dendritic cells in CD8(+) T cell immunity. Nat Immunol. 2004;5:1143-1148.
29. Muranski P, Boni A, Wrzesinski C et al. Increased intensity lymphodepletion and adoptive immunotherapy: how far can we go? Nat Clin Pract Oncol. 2006;3:668-681.

30. Sprent J, Cho JH, Boyman O, Surh CD. T cell homeostasis. Immunol Cell Biol. 2008;86:312-319.

31. Bellone M, Mondino A, Corti A. Vascular targeting, chemotherapy and active immunotherapy: teaming up to attack cancer. Trends Immunol. 2008;29:235-241.

32. Williamson LM, Wimperis JZ, Wood ME, Woodcock B. Fludarabine treatment and transfusion-associated graft-versus-host disease. Lancet. 1996;348:472-473.

33. Hinrichs CS, Palmer DC, Rosenberg SA, Restifo NP. Glucocorticoids do not inhibit antitumor activity of activated CD8+ T cells. J Immunother. 2005;28:517-524.

34. Popat U, Carrum G, May R et al. CD52 and CD45 monoclonal antibodies for reduced intensity hemopoietic stem cell transplantation from HLA matched and one antigen mismatched unrelated donors. Bone Marrow Transplant. 2005;35:1127-1132.

35. Ge X, Brown J, Sykes M, Boussiotis VA. CD134-allodepletion allows selective elimination of alloreactive human $T$ cells without loss of virus-specific and leukemia-specific effectors. Biol Blood Marrow Transplant. 2008;14:518-530.

36. Nagler A, Ackerstein A, Or R, Naparstek E, Slavin S. Adoptive immunotherapy with haploidentical allogeneic peripheral blood lymphocytes following autologous bone marrow transplantation. Exp Hematol. 2000;28:1225-1231.

37. Kennedy-Nasser AA, Brenner MK. T-cell therapy after hematopoietic stem cell transplantation. Curr Opin Hematol. 2007;14:616-624.

38. Amrolia PJ, Muccioli-Casadei G, Huls H et al. Adoptive immunotherapy with allodepleted donor T-cells improves immune reconstitution after haploidentical stem cell transplantation. Blood. 2006;108:1797-1808.

39. Mielke $S$, Nunes R, Rezvani $K$ et al. A clinical-scale selective allodepletion approach for the treatment of HLAmismatched and matched donor-recipient pairs using expanded $\mathrm{T}$ lymphocytes as antigen-presenting cells and a TH9402-based photodepletion technique. Blood. 2008;111:4392-4402.

40. Chen BJ, Cui X, Sempowski GD, Liu C, Chao NJ. Transfer of allogeneic CD62L- memory $T$ cells without graft-versus -host disease. Blood. 2004;103:1534-1541.

41. Anderson BE, McNiff J, Yan J et al. Memory CD4+ T cells do not induce graft-versus-host disease. J Clin Invest. 2003;112:101-108.

42. Anderson BE, Taylor PA, McNiff JM et al. Effects of donor T-cell trafficking and priming site on graft-versus-host disease induction by naive and memory phenotype CD4 T cells. Blood. 2008;111:5242-5251.

43. Fowler DH, Breglio J, Nagel G, Eckhaus MA, Gress RE. Allospecific CD8+ TC1 and TC2 populations in graftversus-leukemia effect and graft-versus-host disease. J Immunol. 1996;157:4811-4821.

Correspondence address: email: dariusz.kowalczyk@uwm.edu.pl 